\title{
Correction to: Surface Creasing-Induced Micropatterned GelMA Using Heating-Hydration Fabrication for Effective Vascularization
}

\author{
Surasak Kasetsirikul ${ }^{1} \cdot$ Dettachai Ketpun $^{1} \cdot$ Yon Jin Chuah $^{2} \cdot$ Yannapol Sriphutkiat $^{1}$ • \\ Dong-An Wang ${ }^{2} \cdot$ Yufeng Zhou ${ }^{1}$
}

Published online: 26 October 2021

(C) The Korean Tissue Engineering and Regenerative Medicine Society 2021

\section{Correction to: Tissue Eng Regen Med Online}

ISSN 2212-5469

https://doi.org/10.1007/s13770-021-00345-0

In the original publication, first author name was incorrectly published as 'Surasak Kasetsiriku'. The correct name should read as "Surasak Kasetsirikul".
Publisher's Note Springer Nature remains neutral with regard to jurisdictional claims in published maps and institutional affiliations.

The original article can be found online at https:// doi.org/10.1007/s13770-021-00345-0.

Yufeng Zhou

yfzhou@ntu.edu.sg

1 School of Mechanical and Aerospace Engineering, Nanyang

Technological University, 50 Nanyang Avenue,

Singapore 639798, Singapore

2 School of Chemical and Biomedical Engineering, Nanyang

Technological University, 62 Nanyang Drive,

Singapore 637459, Singapore 